\title{
Analysis of Teaching-Examination Strategies Based on the National Dental Qualification Test
}

\author{
Xu Zheng ${ }^{1,2}$, Chun Yi Cao ${ }^{3}$, Sheng Ping $\mathrm{Cao}^{4}$, Diwas Sunchuri ${ }^{5}$, Zhu Ling Guo ${ }^{1,2, *}$ \\ ${ }^{1}$ School of Dentistry, Hainan Medical University, Hainan, PR China \\ ${ }^{2}$ Department of Dentistry, The First Affiliated Hospital of Hainan Medical University, Hainan, PR China \\ ${ }^{3}$ Hainan Eye Hospital and Key Laboratory of Ophthalmology, Zhongshan Ophthalmic Center, Sun Yat-sen University, Hainan, PR China \\ ${ }^{4}$ Institute of Clinical, Hainan Medical University, Hainan, PR China \\ ${ }^{5}$ School of International Education, Hainan Medical University, Hainan, PR China
}

Email address:

604569033@qq.com (Zhu Ling Guo)

${ }^{*}$ Corresponding author

\section{To cite this article:}

Xu Zheng, Chun Yi Cao, Sheng Ping Cao, Diwas Sunchuri, Zhu Ling Guo. Analysis of Teaching-Examination Strategies Based on the National Dental Qualification Test. Higher Education Research. Vol. 5, No. 3, 2020, pp. 76-82. doi: 10.11648/j.her.20200503.12

Received: April 17, 2020; Accepted: May 8, 2020; Published: May 28, 2020

\begin{abstract}
Nowadays, the qualification examination of practicing doctors has been one of the important criteria for the selection of health talents in China, while teaching reform has always been the priority in the teaching work of colleges and universities. This paper discusses the significant measures of teaching reform in colleges and universities through its examination results. To explore the test strategies for both Chinese and oversea students from Hainan Medical University based on the status of the qualification examination of practicing doctors in The School of Dentistry. Through the National Medical Examination Center, we collected basic information, average scores and the success rates in various medical sections and different subjects tested in the qualification examinations for dental practitioners who graduated from Hainan Medical University in 2011-2016, which were compared with the national corresponding parts. From 2011 to 2016, the number of practicing doctors taking the dental exam nationwide increased, and accounted for $1.2 \%$ of the number of candidates nationally. In 2016 , the comprehensive written test and total success rates of candidates at Hainan Medical University decreased by nearly $9 \%$ compared with the national average, with a statistically significant difference in the written test results $(P<0.05)$. There were significant differences between the average scores of the clinical medicine section and the basic medical section compared with the national examination results in $2016(\mathrm{P}<0.01)$. According to the results of the examination focusing on different clinical disciplines, the average scores of the 16 courses in 2016 were lower than those of the corresponding parts for the candidates taking the national examination. The teaching reforms and test strategies were proposed based on the factors that affected the test scores. This paper puts forward the oral examination as the focus point for further teaching and emphasizes the need for further students' practical training.
\end{abstract}

Keywords: Licensing Examination for Dental Practitioners, Undergraduate Teaching strategies, Examination Techniques, Dental Education

\section{Introduction}

The Medical Licensing Examination is one of the most important examinations for the identification of medical talents in China, and is also the basis for evaluating the teaching quality of medical colleges and universities at the present moment. The dental examination is composed of a practical skills examination and a comprehensive examination in medicine, surgery and basic medical sciences [1]. Only after passing the practical skills examination can candidates take the comprehensive examination in the same year $[2,3]$. Since the implementation of the Law on Licensed Doctors, not only is the examination related to the admission and management of health practitioners, but also the success rate has become one of the indicators to assess teaching quality in medical colleges and universities $[4,5]$. To be qualified 
doctors, candidates should possess the necessary professional knowledge, clinical thinking, practical skills and professional ethics. Hainan Medical University is the only medical university located in the tropical regions in China. It takes tropical medicine as the basis of its teaching and closely follows the China`s "One Belt, One Road" Strategy and the South China Sea Strategy, recruiting overseas students from 32 other countries, which strengthens educational exchanges and the cooperation with other tropical countries and developing countries along the route [6]. This paper reviews and analyses the six-year examination for dental practitioners in the School of Dentistry at Hainan Medical University from 2011 to 2016 in order to promote teaching reform and improve the rates of students passing the examination.

\section{Materials and Methods}

\subsection{General Information}

The data are derived from the National Medical Testing Center, which including the number of participants, the total scores, the total success rates, the success rates in the comprehensive written examination and practical examination, together with the average scores in various medical subjects and sections in the comprehensive written examination from 2011 to 2016.

\subsection{Statistical Method}

Using the SPSS 23.0 statistical software, an $X^{2}$ test was used to compare the comprehensive written examination, practical skills and the total success rates of undergraduates majoring in dentistry at Hainan Medical University from 2011 to 2016 with the corresponding parts in the national examination. An independent sample test was used to compare the average scores of the dentistry candidates in different medical sections and disciplines in the comprehensive written examination at Hainan Medical University with those of the national candidates. A $t$-test was performed when the data between the two groups was in a normal distribution relationship and using a $t^{\prime}$-test when not. $P<0.05$ was considered statistically different between the two groups and $P<0.01$ showed a significantly statistical difference.

\section{Results}

\subsection{Basic Licensing Examination Information}

From 2011 to 2016, the number of candidates taking the dental examination in China increased year by year. The average number of dental graduates from Hainan Medical University participating in the examination is 55 every year, accounting for $1.2 \%$ of the national candidates. The total rates of students passing the Dentistry licensing examination at Hainan Medical University in 2012-2016 showed a downward trend compared with the total passing rate in our school in 2011 (Figure 1). The total rates of students passing the
Dentistry licensing examination at Hainan Medical University was the same as that of the whole country in 2012 and 2015, which decreased by nearly $9 \%$ compared with that of the whole country in 2016.

\subsection{Average Scores of Medical Sections in the Licensing Examination}

The average scores of the medical sections in the Dentistry licensing examination at Hainan Medical University in 2011, which included the basic medicine section, the clinical medicine section, the dentistry section and the preventive medicine section, were higher than the national average level, but there was no significant difference among the groups $(P>0.05)$, as shown in Figures 2-4. From 2012 to 2016, the average scores of almost each of the medical sections of the Hainan Medical University candidates were lower than the national average. The average scores of the basic medical section from 2014 to 2015 were statistically different from the national average $(P<0.05)$. And the differences between the average scores of the clinical medicine section and the basic medical section in 2016 were significant compared with the national examination results $(P<0.01)$, as shown in Figures $2-4$. The average scores of the preventive medicine section in 2013 and 2016 were statistically different from the national average $(P<0.05)$.

\subsection{Average Scores in Various Subjects in 2016}

In 2016, the candidates' scores of five courses at Hainan Medical University were higher than those of the national candidates, which included medical psychology, medical ethics, obstetrics and gynecology, periodontics and preventive medicine (dentistry), but there were no significant difference between each group compared with the national average level $(P>0.05)$. The average scores of the other 16 courses were lower than those of the national candidates. The average scores of medical immunology, pediatrics and oral mucosal diseases were significantly different from those of national counterparts $(P<0.05)$. The average scores of five courses, including surgery, pediatric dentistry, oral anatomy and physiology, preventive dentistry and oral and maxillofacial surgery, were significantly different from the national average $(P<0.01)$, as shown in Table 1 .

\section{Discussion}

Dentistry licensing examination consists of five parts, which include basic medicine section, medical humanities section, clinical medicine section, dentistry section and preventive medicine section [3]. Among them, the basic medical section is composed of biochemistry, pharmacology, medical microbiology, medical immunology, oral anatomy and physiology, physiology and oral histopathology; the medical humanities section are health regulations, medical ethics and medical psychology; the clinical medicine section are gynecology and obstetrics, pediatrics internal medicine and general surgery; the Dentistry Section are periodontology, 
diseases of the oral mucosa, prosthodontics, cariology and endodontics, oral and maxillofacial surgery and pediatric dentistry; preventive medicine section are preventive medicine and preventive dentistry. At present, the training process for undergraduates majoring in dentistry at Hainan Medical University is divided into three stages, which are respectively the joint examination in seven medical specialties, the joint examination in nine dentistry specialties and the graduation examination. Among them, there is less overlap between the seven subjects involved in the joint examination of medical specialties and the licensing subjects. There is, however, a significant difference between the types of joint examination questions in the nine dentistry specialties and the licensing examination. Similar to other universities in China, the structure of examination papers in the phased assessment is also quite different from that of the licensing examination. In 2016, the success rate in the written examination part of the dentistry licensing examination dropped by nearly $9 \%$ compared with that of the whole country. Students made more mistakes in questions closely related to clinical practice. In view of the phenomenon, our school can expand contents of clinical practice, adjust the exam question types and increase the training on machine-based examination techniques in the stage assessments. The implementation of the joint examination mode and the initiation of practical management courses can not only strengthen students' consolidation of their professional knowledge, but also lay a foundation for the practical operation in the licensing examination [7]. Therefore, Our school should further deepen the assessment of students at all stages in their training for the licensing examination.

In line with some advanced countries, we should develop the curriculum concept, adjust the curriculum setting, improve students' interests, and fully combine theoretical knowledge with practical skills $[2,8]$. According to the data analysis of the licensing examination in 2016, the average scores in pediatrics in the clinical medicine section together with pediatric stomatology, oral mucosa and preventive stomatology in stomatology section were lower than those in the corresponding parts of the national examination with significant differences. These four subjects were not included in the major courses tested in the curriculum design, which leads to the insufficiency of students' subjective attention and study time investment. Therefore, for such courses the licensing examination covers, we can consider setting the final exam consistent with other major courses [9]. The average scores in medical immunology, oral anatomy and physiology in the basic medicine section of Hainan Medical University dentistry candidates were lower than those in the corresponding part of the national examination, and the difference was statistically significant. This situation was due to the difficulty of abstracting knowledge of these two basic disciplines, making it difficult for students to understand, memorize and apply. It also exposed the disadvantages of curriculum design, which made it difficult for students to recall basic knowledge in clinical application. And under the existing teaching conditions, we should enrich the teaching resources and embody the knowledge gained in theoretical courses. At the same time, virtual courses can be effectively utilized to enrich teaching methods and diversify teaching [10, 11]. In addition, surgery and oral and maxillofacial surgery were important components of the licensing examination accounting for $22 \%$ of the total scores. The average scores of the two courses in 2016 were lower than the corresponding part of the national examination with the significant difference, which was because the two courses were closer to clinical practice in form and less related to other clinical disciplines in contents. Therefore, we should strengthen their connection with basic courses such as oral anatomy and physiology in the process of teaching, and combine the skills assessment in the licensing examination with early training in undergraduate study. Previous studies have proved that early clinical experience during training is conducive to medical students' learning and the cultivation of correct concepts and attitudes $[12,13]$. At the same time, we can use PBL, CBL, ward probation and other forms to deepen students' understanding of clinical knowledge and conduct formative assessments [14-16]. In addition to integrating and optimizing the teaching contents to strengthen the curricular understanding and application, oral clinical skills contests can be launched during the school time to stimulate students' enthusiasm for skill learning. Academic lectures and social practice can be used to broaden students' knowledge level and integrate all kinds of knowledge including actual experience with patients [17]. The improvement of practical skills emphasizes the students' comprehensive application of knowledge, which requires a multi-aspect, multi-level and multi-dimensional basis. And what is more needed is long-term subtle influence by avoiding the separation of basic medical sciences and clinical application as well as the disjointing of knowledge and application.

Nearly half of the exam subjects are more than three years away from the candidates' learning stage at school, which requires the cultivation of self-motivated learning ability in the university to promote and guide autonomous learning [18, 19]. Some studies have pointed out that a series of medical education sub-platforms provide students with the opportunity to improve their clinical ability, and at the same time significantly improve their practical ability [20, 21]. Establish curriculum-centered digital autonomous learning platforms, medical simulation education center, national virtual simulation experimental teaching center and medical education "cloud" platform to provide rich teaching resources and skills training environment for students and alumni, and promote students' self-motivated learning [10, 22]. For the study group, we can set up senior-junior grade study groups, and incorporate the team's comprehensive final ranking into the annual scholarship evaluation. Through the sharing of professional notes and learning experience, senior students can lead the professional learning of junior students, help juniors to get in touch with oral clinical knowledge in advance and strengthen the links between basic medical sciences and clinical skills. We can also regularly invite or hire outstanding alumni to communicate with students, such as lectures on case reports, pre-examination tutorial lectures, and other forms of 
experience exchange. Examination-oriented is the first step to open the door of the medical practice. The comprehensive clinical competence and detailed control of medical knowledge are more conducive to improve medical students' professional ability.

At present, the success rate of candidates in the licensing examination is an important evaluation index for the quality of education and teaching in medical colleges and universities. Our University has enrolled international students major in medicine for years and will add a major in Dentistry. The international students will be recruited in the licensing examination for dental practitioners. In order to provide more excellent talents for the social, we should establish our own teaching system according to the current situation, take the dentistry licensing examination as the teaching guidance, optimize curriculum design, enrich teaching resources, guide students to achieve overall development, and realize the "cloud plan" of teaching.

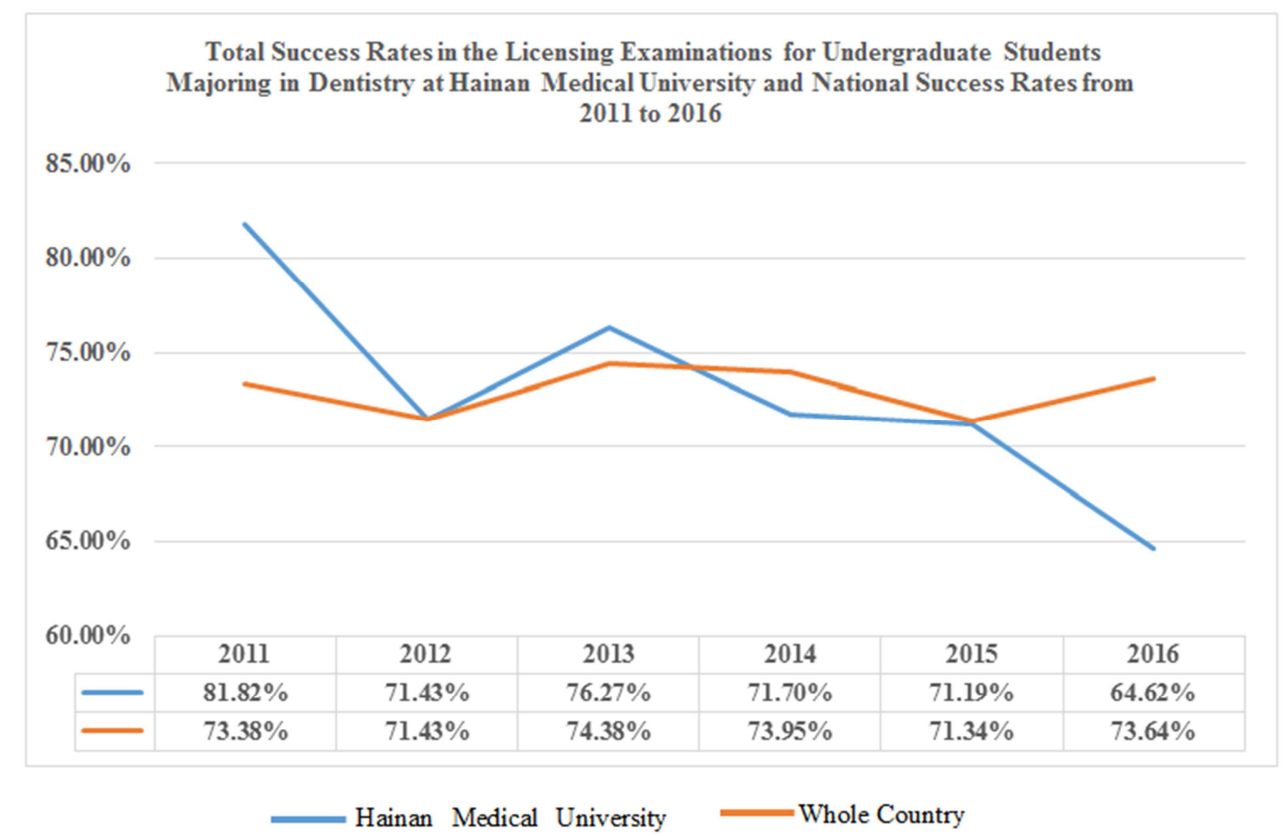

Figure 1. Total Success Rates in the Licensing Examinations for Undergraduate Students Majoring in Dentistry at Hainan Medical University and National Success Rates from 2011 to 2016.

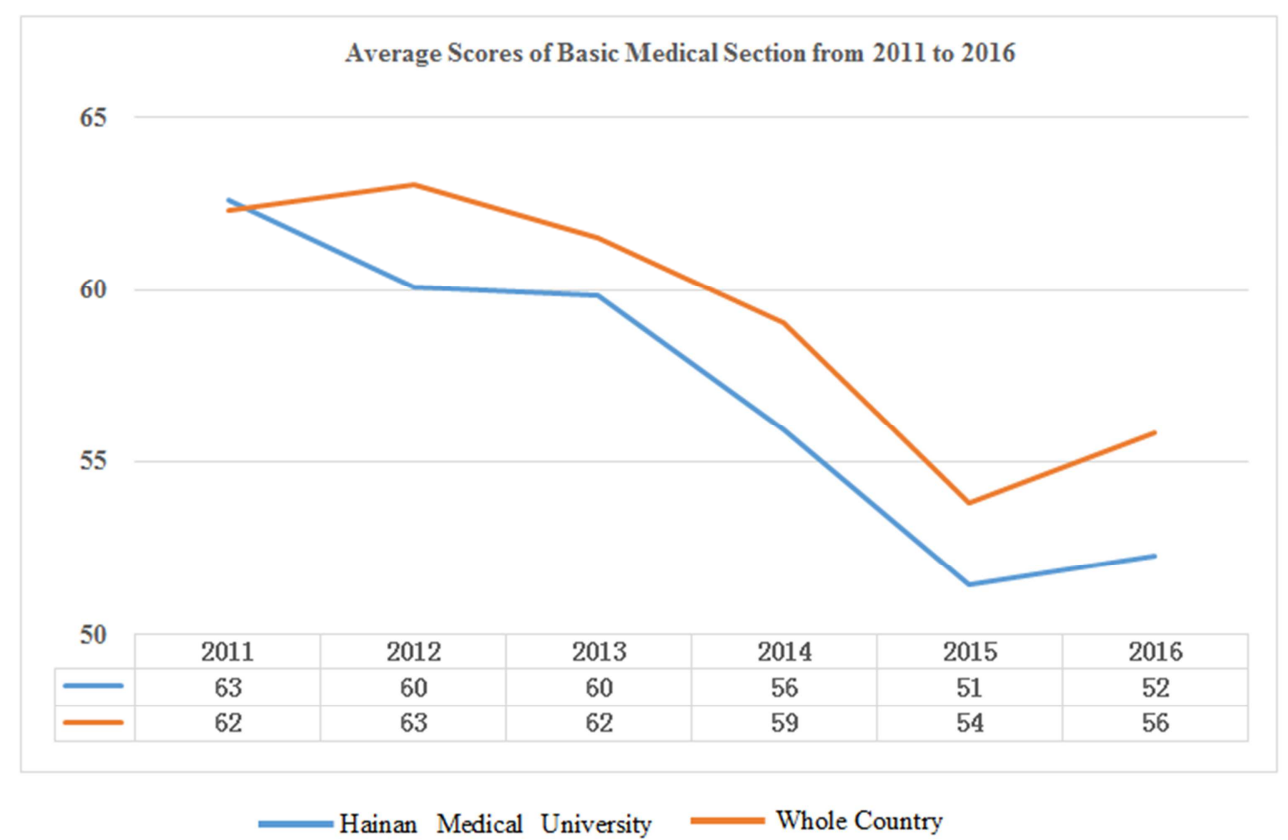

Figure 2. The Average Scores in the Basic Medical Section of the Dentistry Licensing Examination at Hainan Medical University and the National Corresponding Scores in 2011-2016. 


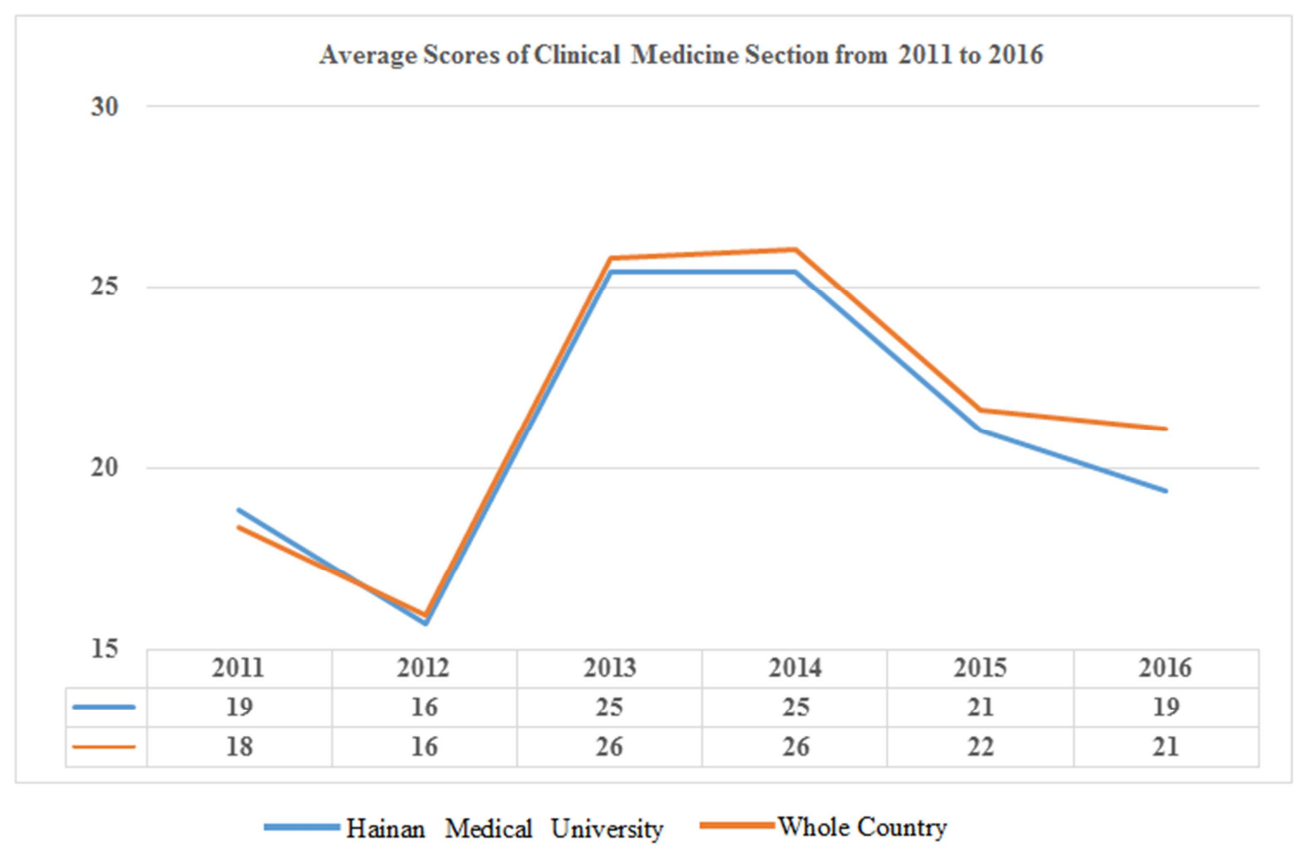

Figure 3. The Average Scores in the Clinical Medicine Section for the Dentistry Licensing Examination at Hainan Medical University and the National Corresponding Scores in 2011-2016.

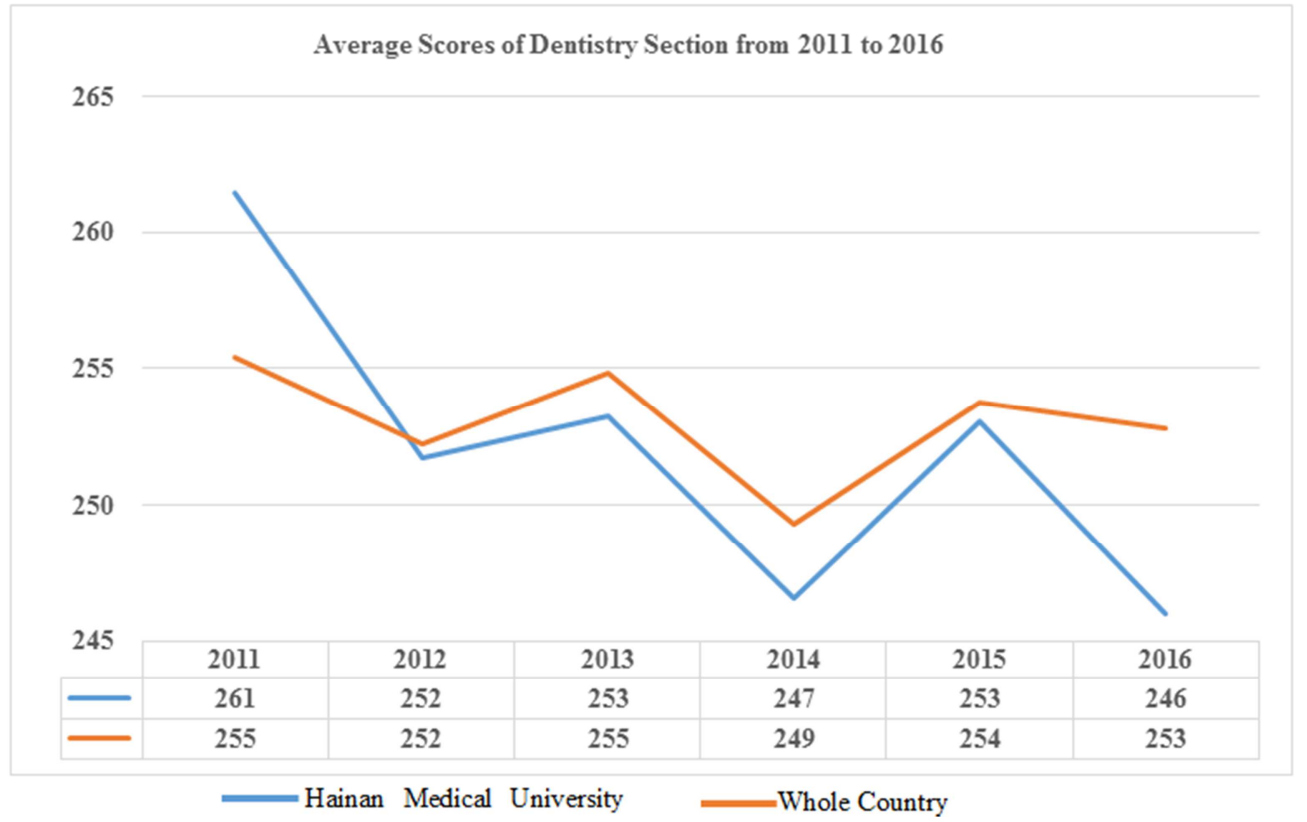

Figure 4. The Average Scores in the Dentistry Section for the Dentistry Licensing Examination at Hainan Medical University and the National Corresponding Scores in 2011-2016.

Table 1. The Average Scores in the Various Subjects in the Comprehensive Written Examination of the Dentistry Licensing Examination at Haiann Medical University and the National Corresponding Scores in 2016.

\begin{tabular}{|c|c|c|c|c|c|c|}
\hline Composition of Dentistry Licensing Examination & Total Scores & Area & Average Scores & Standard Deviation & $\mathbf{t}$ & $\mathbf{P}$ \\
\hline \multicolumn{7}{|l|}{ Basic Medicine Section } \\
\hline Biochemistry & 8 & $\begin{array}{l}1 \\
2\end{array}$ & $\begin{array}{l}3.05 \\
3.37\end{array}$ & $\begin{array}{l}1.56 \\
1.57\end{array}$ & -1.596 & 0.11 \\
\hline Pharmacology & 11 & $\begin{array}{l}1 \\
2\end{array}$ & $\begin{array}{l}5.16 \\
5.45\end{array}$ & $\begin{array}{l}1.48 \\
1.88\end{array}$ & -1.529 & 0.131 \\
\hline Medical Microbiology & 9 & $\begin{array}{l}1 \\
2\end{array}$ & $\begin{array}{l}3.13 \\
3.43\end{array}$ & $\begin{array}{l}1.24 \\
1.55\end{array}$ & -1.889 & 0.064 \\
\hline Medical Immunology & 8 & $\begin{array}{l}1 \\
2\end{array}$ & $\begin{array}{l}2.5 \\
2.97\end{array}$ & $\begin{array}{l}1.39 \\
1.48\end{array}$ & -2.488 & 0.013 \\
\hline Oral anatomy and physiology & 32 & 1 & 20.71 & 3.32 & -2.799 & 0.005 \\
\hline
\end{tabular}




\begin{tabular}{|c|c|c|c|c|c|c|}
\hline Composition of Dentistry Licensing Examination & Total Scores & Area & Average Scores & Standard Deviation & $\mathbf{t}$ & $\mathbf{P}$ \\
\hline \multirow{3}{*}{ Oral Histopathology } & \multirow{3}{*}{34} & 2 & 22.07 & 3.81 & \multirow{3}{*}{-1.44} & \multirow{3}{*}{0.15} \\
\hline & & 1 & 17.74 & 3.95 & & \\
\hline & & 2 & 18.55 & 4.41 & & \\
\hline \multicolumn{7}{|l|}{ Medical Humanities Section } \\
\hline \multirow{2}{*}{ Health Regulations } & \multirow{2}{*}{11} & 1 & 6.61 & 1.64 & \multirow{2}{*}{-1.352} & \multirow{2}{*}{0.176} \\
\hline & & 2 & 6.9 & 1.68 & & \\
\hline \multirow{2}{*}{ Medical Psychology } & \multirow{2}{*}{10} & 1 & 7.21 & 1.27 & \multirow{2}{*}{0.475} & \multirow{2}{*}{0.635} \\
\hline & & 2 & 7.13 & 1.32 & & \\
\hline \multirow{2}{*}{ Medical Ethics } & \multirow{2}{*}{9} & 1 & 5.73 & 1.07 & \multirow{2}{*}{0.125} & \multirow{2}{*}{0.9} \\
\hline & & 2 & 5.71 & 1.25 & & \\
\hline \multicolumn{7}{|l|}{ Clinical Medicine Section } \\
\hline \multirow{2}{*}{ Medicine } & \multirow{2}{*}{18} & 1 & 6.66 & 1.72 & \multirow{2}{*}{-1.631} & \multirow{2}{*}{0.103} \\
\hline & & 2 & 7.08 & 2.02 & & \\
\hline \multirow[t]{2}{*}{ Surgery } & \multirow{2}{*}{18} & 1 & 6.16 & 2.27 & \multirow{2}{*}{-3.181} & \multirow{2}{*}{0.001} \\
\hline & & 2 & 7.09 & 2.29 & & \\
\hline Pediatrics & \multirow[t]{2}{*}{6} & 1 & 2.29 & 1.3 & -2397 & 0.017 \\
\hline & & 2 & 2.7 & 1.34 & -2.591 & \\
\hline Obstetrics and Gynecology & 6 & $\begin{array}{l}1 \\
2\end{array}$ & $\begin{array}{l}4.26 \\
4.24\end{array}$ & $\begin{array}{l}1.01 \\
1.09\end{array}$ & 0.144 & 0.886 \\
\hline Dentistry Section & & & & & & \\
\hline Oral and Maxillofacial Surgery & 114 & 1 & 74.81 & 9.09 & -2598 & 0009 \\
\hline Oral and Maxilloracial surgery & 114 & 2 & 77.99 & 9.59 & -2.598 & 0.009 \\
\hline Prosthodontics & 112 & 1 & 77.16 & 9.37 & -1751 & 008 \\
\hline Prostnodontics & 112 & 2 & 79.41 & 10.07 & -1.101 & 0.08 \\
\hline Cariology and Endodontology & 60 & 1 & 42.74 & 5.13 & -0.393 & 0694 \\
\hline & & 2 & 42.99 & 4.98 & & \\
\hline Periodontology & 40 & 1 & 31.03 & 3.39 & 0.944 & 0.349 \\
\hline Pentiventitugy & & 2 & 30.62 & 4.26 & & \\
\hline Diseases of Oral Mucosa & 14 & 1 & 7.47 & 2.34 & -2.392 & 0.017 \\
\hline & & 2 & 8.2 & 2.39 & & \\
\hline Pediatric Dentistry & 20 & 1 & 12.82 & 2.11 & -2.844 & 0.004 \\
\hline Preventive Medicine Section & & 2 & 13.59 & 2.12 & & \\
\hline & & 1 & 4.65 & 1.11 & & \\
\hline Preventıve Medıcine (Oral) & 6 & 2 & 4.5 & 1.09 & 1.077 & 0.281 \\
\hline Preventive Dentistry & 54 & 1 & 32.95 & 4.2 & -2.641 & 0.008 \\
\hline Preventive Dentistry & 54 & 2 & 34.57 & 4.81 & -2.041 & \\
\hline
\end{tabular}

1: Haiann Medical University.

2: Whole Country.

\section{Funding}

This research was funded by Scientific Research Fund of Hainan Provincial Education Department (Hnky2020ZD-19), Young Talents' Science and Technology Innovation Project of Hainan Association for Science and Technology (QCXM201817), Medical Education Research Project of Medical Education Branch of Chinese Medical Association (2018B-N12003), Health Science Research Project of Hainan Province (19A200062), Course Construction Project of Hainan Medical University (HYJW201834), Education Science Research Project of Hainan Medical University (HYZX201704), Marxism Theory Discipline Research Project of Hainan Medical University (QMYKYLX201807), Research Project of Hainan Provincial Humanities Medical Research Base (QRYZH201811 (YB)).

\section{Acknowledgements}

The authors would like to acknowledge the extensive administrative and technical support from the First Affiliated Hospital of Hainan Medical University.

\section{References}

[1] Yunxia Geng, Liying Zhao, Yu Wang, et al. Competency model for dentists in China: Results of a Delphi study. PLoS One, 2018, 13 (3).

[2] Wu ZY, Zhang ZY, Jiang XQ, Guo L. Comparison of dental education and professional development between mainland China and North America. Eur J Dent Educ 2010: 14: 106-112.

[3] Y. H. Wang, Q. Zhao, Z. Tan. Current differences in dental education between Chinese and Western models. European Journal of Dental Education, 2016, 21 (4): e43-e49.

[4] Janice A. Brannon, Ellen R. Cohn, Jana Cason. Making the Case for Uniformity in Professional State Licensure Requirements. Int J Telerehabil, 2012, 4 (1): 41-46.

[5] SohailBajammal, Rania Zaini, WesamAbuznadah, et al. The need for national medical licensing examination in Saudi Arabia. BMC Med Educ, 2008, 8: 53.

[6] Jie Li, Fangjin Xu, ZhaojunSun, et al. Regional differences and spatial patterns of health status of the member states in the"Belt and Road'Initiative. PLoS ONE, 2019, 14 (1). 
[7] Muhammad Ashraf Nazir, Faisal Izhar, Kalsoom Tariq, et al. A cross-sectional study of dentists about the need for a practice management course in undergraduate dental program. Eur J Dent, 2018, 12 (4): 508-515.

[8] Nicole Rafai, Martin Lemos, Lieven Nils Kennes, et al. Anatomy meets dentistry! Linking anatomy and clinical practice in the preclinical dental curriculum. BMC Med Educ, 2016, 16.

[9] Cheryl B Stetler, Marcia W Legro, Carolyn M Wallace, et al. The Role of Formative Evaluation in Implementation Research and the QUERI Experience. J Gen Intern Med, 2006, 21 (Suppl 2): S1-S8.

[10] C. Shi, L. Wang, X. Li, et al. Virtual classroom helps medical education for both Chinese and foreign students. European Journal of Dental Education, 2014, 19 (04): 217-221.

[11] A. J. Ireland, A. S. A. Smith, D. M. Alder, et al. Building a learning community on-line: the first step towards a national virtual learning environment in orthodontics. Journal of Orthodontics, 2005, 32 (03): 214-219.

[12] Littlewood S, Ypinazar V, Marqolis SA, et al. Early practical experience and the social responsiveness of clinical education: systematic review. BMJ, 2005, 331 (7513): 387-91.

[13] N J Pohontsch, A Stark, M Ehrhardt, et al. Influences on students' empathy in medical education: an exploratory interview study with medical students in their third and last year. BMC Medical Education, 2018, 18: 231.

[14] Hans M Bosse, SoerenHuwendiek, Silvia Skelin, et al. Interactive film scenes for tutor training in problem-based learning (PBL): dealing with difficult situations. BMC Med Educ, 2010, 10: 52-68.
[15] Susan F. McLean. Case-Based Learning and its Application in Medical and Health-Care Fields: A Review of Worldwide Literature. J Med EducCurric Dev, 2016, 3.

[16] KamalShigli, Y. B. Aswini, Deepti Fulari, et al. Case-based learning: A study to ascertain the effectiveness in enhancing the knowledge among interns of an Indian dental institute. J Indian ProsthodontSoc, 2017, 17 (1): 29-34.

[17] Amy Baernstein, Anne-Marie E, AmiesOelschlager, et al. Learning Professionalism: Perspectives of Preclinical Medical Students. Aca Med, 2009; 84: 574-581.

[18] M. Manogue, J. McLoughlin, C. Christersson, et al. Curriculum structure, content, learning and assessment in European undergraduate dental education-update 2010. European Journal of Dental Education, 2011, 15 (03): 133-141.

[19] Ernesto Panadero. A Review of Self-regulated Learning: Six Models and Four Directions for Research. Front Psychol, 2017, 8: 422 .

[20] Kearney RC, Premaraj S, Smith BM, et al. Massive open online courses in dental education: two viewpoints: viewpoint 1 : massive open online courses offer transformative technology for dental education and viewpoint 2: massive open online courses are not ready for primetime [J]. J Dent Educ, 2016, 80 (2): 121-127.

[21] Stokes CW, Towers AC, Jinks PV, et al. Discover Dentistry: encouraging wider participation in dentistry using a massive open online course (MOOC) [J]. Br Dent J, 2015, 219 (2): $81-85$

[22] X. Gao, L. M. Wong, D. Y. S. Chow, et al. Learning clinical procedures through Internet visual resources: A qualitative study amongst undergraduate students. European Journal of Dental Education, 2014, 19 (01): 38-43. 